\title{
O objeto das ciências sociais e a virada comunicativa: Adorno após Habermas
}

Gisela Catanzaro e Ezequiel Ipar

A impugnação habermasiana do pensamento de Adorno

Ao fundamentar a passagem do paradigma da produção para o da ação comunicativa no campo da teoria social, Jürgen Habermas realizou um breve e contundente ajuste de contas com a primeira geração da Escola de Frankfurt. Apoiado numa virada linguística de orientação pragmático-racionalista, o novo paradigma teórico precisou confrontar algumas teses relevantes do pensamento de Theodor Adorno para que a teoria crítica pudesse aspirar a um critério de cientificidade válido. Desdobrada com ênfase a partir da década de 1980, a ruptura com Adorno foi construída a partir de três críticas: em primeiro lugar, a crítica de seu diagnóstico do capitalismo tardio; em segundo, a crítica de sua teoria das patologias da razão e, em terceiro, a crítica - derivada das anteriores - da relação negativa que o pensamento de Adorno mantinha com os fundamentos das ciências sociais.

Neste trabalho discutiremos a interpretação habermasiana com a dupla intenção de refletir criticamente sobre alguns pressupostos e efeitos da "virada comunicativa" e de repensar as potencialidades do pensamento de Adorno para as ciências sociais contemporâneas. 


\section{0 conceito de mundo administrado}

A primeira razão que Habermas esgrime a favor de uma mudança de paradigma na teoria crítica da sociedade se refere às imprecisões, aos enganos e, por fim, à falsidade do diagnóstico apresentado por Adorno e Horkheimer acerca do capitalismo tardio (cf. Habermas, 1987a, pp. 465 e ss.; Honneth, 1995, pp. 67-69). O diagnóstico sombrio dos seus predecessores dependeu da redução do extenso e complexo processo de racionalização social iniciado pela modernidade europeia no século XVIII às suas consequências "menos esperadas": o totalitarismo político, a concentração e a burocratização econômicas e a progressiva desdiferenciação e mercantilização das distintas esferas da produção cultural. Esse diagnóstico retomava unilateralmente os aspectos negativos que a teoria weberiana tinha encontrado no processo de racionalização do mundo social; algo como o momento kafkiano das teses que destacavam uma progressiva perda de liberdade e sentido nas sociedades organizadas segundo os critérios da racionalidade instrumental. A partir dessa perspectiva, aquilo que Adorno e Horkheimer ofereceram como marco interpretativo capaz de efetuar uma releitura crítica do projeto original do Iluminismo, bem como de suas instituições políticas e culturais, teria sido elaborado ora nos termos de uma "teoria do fascismo", ora de uma "teoria da cultura de massas". Com ambas as teorias os autores pretendiam - e aqui radica o engano que Habermas quer ressaltar - dar conta da nova fase do capitalismo em seus aspectos econômicos, psicológicos, políticos e culturais.

A opinião de Habermas é a de que esse diagnóstico sombrio sobre a modernidade só podia se justificar na época sinistra na qual a Dialética do esclarecimento fora escrita, sendo a sua extrapolação para além desse contexto histórico preciso muito prejudicial para o desenvolvimento posterior da teoria crítica (cf. Honneth, 1995, p. 70). Quando consideraram o processo de modernização social a partir do prisma oferecido por fenômenos como a burocratização da atividade econômica, o totalitarismo político e a padronização da cultura, Adorno e Horkheimer incorreram em sérios enganos histórico-empíricos. Tais enganos poderiam ser facilmente rechaçados por uma análise histórica que abordasse os progressos e retrocessos do processo de modernização europeu em seu conjunto. Essa análise permitiria constatar que, junto com a linha regressiva que conduz da revolução industrial até Auschwitz, existe também uma difícil linha evolutiva que parte das lutas sociais do século XVIII e chega à consolidação da economia de bem-estar, à democracia constitucional e à vigência jurídica dos direitos humanos. A 
unilateralidade do diagnóstico sociológico que se fixa obsessivamente no lado obscuro da modernidade deteriora a explicação da totalidade desse processo.

No entanto, esse erro na análise empírica da história não seria tão sério se não houvesse conduzido, por sua vez, à consolidação de graves falsidades no marco teórico utilizado para efetuar a crítica da sociedade. Para compreender a crítica habermasiana, é fundamental explicitar a conexão necessária que ele encontra entre as falhas do diagnóstico sombrio da modernidade e os déficits teóricos dos principais conceitos utilizados por Adorno e Horkheimer da Dialética do esclarecimento até a Dialética negativa.

Segundo a interpretação de Habermas, a radicalização do momento kafkiano da teoria da racionalização weberiana deixou os autores aquém de Weber no que se refere à possibilidade de construir um conceito de ação social não redutor da complexidade das esferas diferenciadas de ação e validade da modernidade; o que, por sua vez, os impediu de elaborar um conceito relacional de poder, apto à compreensão da dinâmica diferenciada dos conflitos intersubjetivos, sem os reduzir a nenhum critério superior totalizante (como fez o marxismo vulgar).

Em sintonia com o programa habermasiano, Axel Honneth (1995, p. 68) em seus primeiros trabalhos teóricos considera que a causa profunda desses déficits da teoria crítica deve ser procurada na releitura da economia política de Marx realizada por Friedrich Pollock entre os anos de 1920 e 1930. Para Pollock, a fase monopolista do capitalismo transformou radicalmente a relação previamente existente entre a economia e as instituições estatais, sujeitando as determinações do mercado a uma planificação centralizada da produção e do consumo que respondia a interesses eminentemente políticoadministrativos. Nesses termos, o capitalismo pós-liberal determinaria uma "superação do capitalismo" dentro do próprio capitalismo, situação histórica que ele chamou de "capitalismo de Estado" (Staatskapitalismus) (Pollock, 1989). Honneth não hesita em afirmar que esse diagnóstico decorria de uma leitura funcionalista de Marx, que teria levado Pollock - e, junto com ele, Adorno e Horkheimer -, de um lado, a negar as linhas de continuidade entre capitalismo pós-liberal e capitalismo de mercado e, de outro, a subestimar a vigência dos conflitos sociais de classe dentro da nova fase (cf. Idem, pp. 70 e ss.). Essa negação e subestimação no plano da economia política teriam sido generalizadas pelas análises psicológicas e culturais da Dialética do esclarecimento. Diante da pergunta "por que os indivíduos toleram sem resistência essa nova forma de controle?”, a primeira geração da escola de Frankfurt ressaltaria unilateralmente a neutralização das 
energias emancipatórias do sujeito pelos aparelhos repressivos e ideológicos do Estado capitalista.

Ao constatar que as teses fundamentais do livro de Adorno e Horkheimer se apoiam em um "marxismo funcionalista", Honneth reproduz e amplia a análise crítica de Habermas. Em sua opinião, essas teses concebem a subjetividade e a cultura como meros elementos funcionais na reprodução da dominação capitalista. Tal funcionalismo teórico (involuntário) - que termina negando no plano do sujeito e da cultura a possibilidade de resistência em face do poder - restringia a potência explicativa da teoria crítica e limitava sua capacidade de projetar um horizonte de racionalidade a partir do qual pudesse expor, em termos normativos imanentes, as insuficiências, as repressões e as irracionalidades da sociedade estudada. Desse modo, os contornos de um conceito crítico de racionalidade se desvanecem, pois, de um lado, a teoria assume traços de uma contemplação de tipo bastante tradicional - que nega suas relaçóes com a prática - e, de outro, delega à arte a competência para expor uma razão que não poderá ser evocada senão por via indireta. Por fim, Honneth poderia afirmar - junto com Habermas - que "essa autossupressão do pensamento filosófico em termos da 'dialética negativa' conduz a aporias" que nos impõem perguntar "se tal estado da questão não será resultado de uma teoria prisioneira da filosofia da consciência, reduzida à relação entre subjetividade e autoconservação" (Habermas, 1987a, p. 466).

\section{A radicalização da análise das patologias da razão}

As insuficiências teóricas encontradas por Habermas nas explicações de Adorno e Horkheimer sobre a nova conformação das sociedades pós-liberais determinam, assim, uma radicalização nociva da análise filosófica acerca das patologias da razão. Seguindo pensadores "malditos" da modernidade-como Sade, Nietzsche e o próprio Kafka -, os autores teriam recaído numa dilaceração da razão subjetiva, que para eles era a responsável pela "instrumentalização" violenta do processo social de racionalização por uma racionalidade objetiva insanavelmente caduca (daí o caráter de contradição performativa dessa crítica da razão). A grande filosofia, que continha a ideia da reconciliação entre natureza e espírito, havia sucumbido junto com as imagens religioso-metafísicas do mundo, mas seguiria guardando a promessa de uma situação "verdadeiramente humana". Jazia sob suas ruínas a verdade capaz de conceder ao pensamento crítico tanto a força negadora como a capacidade para transcender a "coisificação da razão". 
Conforme a reconstrução habermasiana, o processo de "coisificação" da cultura moderna implica uma "coação que leva a assimilar as relaçôes inter-humanas (e a subjetividade) ao mundo das coisas, coação que se produz quando as ações sociais já não são coordenadas através de valores, de normas ou do entendimento linguístico, senão através do meio valor de troca" (Idem, p. 484). Situando historicamente a coisificação nos marcos das problemáticas sociais dos séculos XIX e XX, Habermas - junto com Lukács - diagnostica desequilíbrio e unilateralização na implementação das potencialidades abertas pela modernização cultural. $\mathrm{O}$ desequilíbrio e a unilateralização dependem inteira e exclusivamente dos caminhos seguidos pela racionalização social quando conduzida a partir da seletividade que o capitalismo impõe ao processo de modernização cultural.

Na direção contrária, Adorno e Horkheimer teriam generalizado o conceito de coisificação, descontextualizando e introduzindo-o numa filosofia negativa da história. A generalização implicou tal radicalização da análise das patologias sociais da razão, que tornou virtualmente impossível a elucidação da nova "norma de verdade" (detrás da qual estava a teoria crítica desde o começo). O critério que deveria suplantar a racionalidade objetiva em seu próprio território se perde completamente quando a ideia de verdade permanece associada a uma reconciliação universal de teor romântico, posto que essa reconciliação - pelo seu próprio excesso - estenderia agora a exigência de relações não violentas para a "interação do homem com a natureza: com os animais, as plantas e os minerais" (Idem, p. 485).

\section{A frustração teórica}

O diagnóstico sombrio da modernidade e a perda de um horizonte filosófico que permitisse fundamentar criticamente uma "nova norma de verdade" conduziram a uma concepção contraditória da condição humana: presa entre a vigência irrefletida da razão subjetiva - que postula um princípio de autoconservação incapaz de neutralizar seu caráter autodestrutivo - e a lembrança impotente da razão objetiva - que postula anacronicamente uma unidade indiferenciada de espírito e natureza. Partindo dessa contradição objetiva, Horkheimer criticou tanto as tentativas neopositivistas como as neoontológicas, respectivamente vinculadas a cada um dos polos unilaterais da contradição. Por isso, foi procurar junto com Adorno a racionalidade anterior à racionalidade (instrumental) no conceito de mimesis. Deste dependeria tanto a sua teoria da reconciliação universal - entendida como conformação de 
relações não violentas generalizáveis - como o novo horizonte normativo de verdade (vinculado a uma dimensão socioafetiva que transcende o espaço das relações não violentas da racionalidade intersubjetiva). Mas justamente por isso seria impossível uma "teoria" da mimesis que pudesse dar conta racionalmente da unidade entre identidade e não identidade, entre espírito e natureza. A Dialética do esclarecimento torna-se, assim, uma perspectiva paradoxal e afastada da possibilidade de fundamentar criticamente a teoria das ciências sociais, pois "assinala, para a autocrítica da razão, o caminho que conduz à verdade, questionando simultaneamente a possibilidade de que nesta etapa de estranhamento consumado a ideia de verdade resulte ainda acessível" (Idem, p. 488).

$\mathrm{Na}$ interpretação habermasiana, Adorno não quis sair dessa aporia. A Dialética negativa seria ambas as coisas ao mesmo tempo: tentativa de circunscrever o que discursivamente não se pode dizer - devido à coisificação da cultura - e advertência contra qualquer tentativa de acessar conceitualmente um nível de objetividade superior - no estilo hegeliano - para então fundar a crítica das unilateralidades e dos efeitos repressivos da instrumentalização da razão subjetiva. Diante dessa situação, a Teoria estética, por sua vez, encarrega-se apenas de transferir as competências do conhecimento para a arte, pois supõe nesta última a faculdade mimética de adquirir a forma de um conhecimento objetivo, graças à unidade aberta e não violenta que estabelece entre seus materiais e a estrutura formal que produz o conteúdo espiritual de cada obra (cf. Adorno, 1997d). Com isso, Adorno teria renunciado também às pretensões mínimas de uma autêntica teoria, já que o tipo de conhecimento não conceitual constitutivo da arte é incapaz de enunciar as pretensões de validez universal inerentes ao discurso teórico. A arte sempre oferece algo que resulta mais real e mais fictício, mais objetivo e mais subjetivo, mais fiel e mais enviesado, mais explícito e mais hermético; enquanto o discurso pode aspirar validade teórica graças ao reconhecimento universal de uma multiplicidade diferenciada de subjetividades competentes. Ora, se a mimesis estética não produz nenhum conhecimento teórico acerca da realidade que expóe, e se o conhecimento discursivo é incapaz de traspassar por seus próprios meios a coisificação da cultura, a Dialética negativa e a Teoria estética apenas remeteriam "impotentes" uma à outra.

Para Habermas, o discurso da Dialética do esclarecimento teria significado, portanto, uma ruptura no processo de autoclarificação da razão. Tal perda teria, por sua vez, conduzido a uma infrutífera "estetização" dos problemas 
teóricos que supunha o "abandono da cientificidade" como critério que devia ser estabelecido pela teoria crítica, em termos tanto normativos como práticos. O diagnóstico do impasse é muito claro: limitações inerentes à filosofia da consciência - incapaz de completar a crítica da razão (subjetiva) instrumental e o programa de uma teoria crítica da sociedade - teriam impedido Adorno e Horkheimer de chegarem a um modelo alternativo como aquele oferecido pela teoria da ação comunicativa.

As teses esquecidas de Adorno: rememoração da natureza e primazia do objeto

O conjunto de razões apresentadas por Habermas em favor de uma mudança de paradigma continua delimitando as posições que tentam fundamentar uma perspectiva crítica das ciências sociais. A rigorosa distinção entre os planos da facticidade e da validade social funciona como requisito indispensável para qualquer perspectiva teórica que pretenda superar os efeitos da coisificação cultural. Todavia, ao diagnosticar posiçôes românticas (e estetizantes) em Adorno e desenvolver o paradigma da ação comunicativa, Habermas não critica apenas a vigência oculta da filosofia da história nas ciências sociais. Com esse movimento teórico ele também obstrui a reconsideração daquelas teses adornianas que não entram facilmente no esquema romântico-historicista que sua crítica atribui.

Diferentemente do projeto geral da teoria da ação comunicativa, Adorno e Horkheimer evitaram uma "superação" da coisificação no plano da pura teoria. Tendo em vista as contradições e os paradoxos da razão moderna, eles atribuíram ao pensamento crítico a exigência de sustentar-se no abismo para compreender o desdobramento dialético de cada um dos termos. O que estava implícito nesse movimento teórico era a resistência à apressada identificação entre o desejo de realizar uma liberação ainda pendente (intrínseco a todo projeto de teoria crítica) e a celebração teórica de uma vitória consumada. Para os autores, a tarefa da reflexão crítica exigia a "reativação da dialética interna do esclarecimento" por meio da autocrítica durante o próprio processo de formação de conceitos:

[...] cada progresso da civilização renovou, junto com o domínio, também a perspectiva para sua mitigação. A realização dessa perspectiva depende do conceito. Pois este não se limita só a distanciar, enquanto ciência, aos homens da natureza, mas também, enquanto autorreflexão do pensamento [...], permite medir a distância que eterniza a injustiça (Adorno e Horkheimer, 1997, p. 58). 
É no contexto dessa crítica conceitual do pensamento conceitual que aparece uma tese central da Dialética do esclarecimento: "mediante a rememoração [Eindenken] da natureza no sujeito, em cuja realização se encerra a verdade desconhecida de toda cultura, o Iluminismo se opõe ao domínio enquanto tal" (Idem, ibidem). Essa observação parece justificar a crítica habermasiana que descobre nela o ressaibo romântico de uma imagem metafísica do mundo. Faz-se necessário, então, começar analisando, sumariamente, a distância e a diferença que separa a perspectiva de Adorno do "redescobrimento" romântico da natureza.

\section{A natureza romântica: duas emergências}

Conforme sustenta Herder (1986) em sua "metacrítica à Crítica da razão pura", as ausências, na arquitetura do sujeito transcendental kantiano, de uma fisiologia das forças humanas implicadas no conhecimento e de uma reflexão sobre o papel da linguagem, no processo de formação da razão, determinaram os principais déficits do criticismo. É sob a luz desses déficits que se define a nova tarefa de uma filosofia realmente crítica: formular a crítica da linguagem e traçar a genealogia da razão para descobrir a origem sensorial e corporal do cogito. Tal redescobrimento aparece, por sua vez, como contraste ao "papismo regulamentador" para o qual tendia o entendimento dogmático, amnésico de seu substrato corporal; esquecimento que a crítica deveria corrigir pensando seu próprio enraizamento na natureza.

A lembrança da natureza sob o cogito conduz, de um lado, à postulação da indiferenciada unidade "do vivente" ("animado por um mesmo espírito") e, de outro, à estruturação internamente hierarquizada desse ininterrupto e harmônico fluxo vital. Nos termos do próprio Herder (Idem, pp. 61-78), a "lembrança da natureza" propicia a compreensão do humano como "revelação de uma mesma força espiritual que atravessa todo o vivente". Não obstante, essa força espiritual alcança no homem "a máxima finura a que podia chegar em uma estrutura terrestre", tornando-o capaz de "colocar-se fora do corpo, e até fora do mundo, e dirigi-lo" (Herder, 1959, p. 135). Desse modo, a natureza "relembrada" do romantismo é o substrato pré-discursivo de uma filosofia que segue tentando elucidar a dimensão constituinte do sujeito a partir de sua capacidade incondicionada de devir agente doador de sentido.

Pelo contrário, para Adorno e Horkheimer o que está em jogo na "rememoração da natureza" é a possibilidade de fazer consciente a relação entre a constituição unilateral do sujeito e as atuais relaçôes de dominação. A "re- 
memoração da natureza no sujeito" abre uma reflexão crítica da dominação espiritual do mundo e não a procura por um hipotético substrato compartilhado entre a natureza e a cultura. A "rememoração" torna evidente a gênese violenta do espírito, bem como o caráter falsamente centrado do círculo no qual rememora sua genealogia. Diferentemente da concepção metafísica do romantismo, portanto, Adorno e Horkheimer procuram elaborar uma crítica do "círculo narcisista" que institui a cultura moderna. Esse narcisismo bloqueia uma e outra vez o desdobramento do conteúdo utópico do moderno e garante a solidariedade da reflexão racional com o esquecimento da sua própria unilateralidade (e das possibilidades históricas de liberação).

Como discutiremos adiante, a crítica dessa unilateralidade subjetiva constitui um dos motivos centrais da tese adorniana sobre "primazia do objeto", o que exige uma leitura conjunta de ambas. Por enquanto recordaremos apenas que, ao identificar a realização da razão objetiva com o império da razão subjetiva, essa unilateralidade desconhecida também permitiu à razão liberada do além supraterrestre - consolidar seu compromisso com o domínio.

Ora, a Dialética do esclarecimento exige uma segunda precisão em relação à noção de uma "rememoração da natureza" que corresponde, dessa vez, à diferença entre a tese defendida pelos autores e o culto neorromântico da vivacidade da natureza. Conforme assinalam Adorno e Horkheimer a propósito das tentativas românticas de revalorização do corpo nos séculos XIX e XX, nas apelações à vitalidade da natureza se oculta também a idealização de algo morto e mutilado; idealização que se sustenta, por sua vez, no desconhecimento do processo constante que reduziu a natureza a um material (manipulável) de domínio: "O corpo físico [Körper] não pode transformar-se novamente em corpo vivente [Leib]. Continua sendo um cadáver, ainda que seja fortalecido" (Adorno e Horkheimer, 1997, p. 267). Assim, “a natureza” não poderia pôr em questão a práxis dominante, já que

[...] como modelo e meta ela representa o antiespírito, a mentira e a bestialidade; só na medida em que é conhecida e reconhecida como tal se converte no impulso do existente em direção a sua própria paz, na consciência que animou do começo a resistência imperturbável contra os chefes e o coletivo (Idem, p. 292).

Esse mundo submetido e igualado a mero material de domínio revela-se sempre o mesmo e sua contrapartida é a identidade abstrata da racionalidade subjetiva. Desse modo, por muito que o romantismo a imagine como fonte de vida e como alternativa, a natureza não faz mais que refletir 
a indiferença e a identidade existentes entre uma subjetividade fechada sobre si mesma e um mundo objetivo falso e bestial.

A partir dessa rápida passagem pelas objeções de Adorno e Horkheimer às teses que postulam um acesso irrefletido à positividade de uma natureza idealizada, fica claro que não se trata nem de reconstruir nem de permanecer à espera de uma racionalidade objetiva de corte romântico-historicista. Diferentemente de Habermas, que associa inequivocamente a Dialética do esclarecimento, a Dialética negativa a Teoria estética ao romantismo, consideramos necessário recorrer a outras fontes teóricas para compreender a autocrítica do pensamento conceitual que essas obras propõem. Nesse sentido, é o próprio Adorno que, alguns anos mais tarde, retoma essa questão apresentando teses que propõem a "primazia do objeto" em filosofia e estética. A reconstrução dessas teses nos servirá para reformular a problemática geral.

\section{A primazia do objeto}

Em um texto publicado tardiamente sob o título "Sobre sujeito e objeto", Adorno formula a estranha tese de que, ao interior da autocrítica do pensamento conceitual, corresponderia sustentar uma "primazia do objeto" (Vorrang des Objekts). Apresentada como corretivo da unilateralidade da subjetividade dominante, a tese parece implicar uma virada "objetivista" cujo conteúdo e alcance para a fundamentação crítica da teoria social Habermas desconhece. O desconcerto é razoável, dado que Adorno postula essa "primazia do objeto" no marco de uma radicalização da crítica da coisificação da cultura. Para medir mais uma vez a distância que existe entre a proposta de Adorno e as interpretações que pretendem sua superação, detenhamo-nos brevemente nessa segunda tese.

A "virada objetivista" de Adorno põe em questão, de saída, a ideia de que o objeto de conhecimento possa ser construído integralmente a partir dos recursos disponíveis nos distintos campos do saber. Esse questionamento revela o objeto da reflexão como problema que se impõe ao pensamento, demandando-lhe o esforço de produzir sua conceitualização. Mas vejamos agora em que consistiria essa virada. Melhor: qual é a índole desse movimento e em relação a que ele se realiza? Este último aspecto já foi discutido: ele se realiza em relação aos modos ordinários da crítica. Mas, então, qual seria o objeto problemático implicado na "virada objetivista"?

As indicações do texto sugerem que a instância do objeto se transforma em momento essencial da crítica do conhecimento ali onde contradiz a 
pretensão de "aferrar a totalidade do real através da força do pensamento" (Adorno, 1997f, p. 73). Quando essa pretensão se realiza em meio à coisificação do mundo contemporâneo, por meio do procedimento que o saber instituído considera adequado, o conhecimento não serve a "outra coisa mais que para velar a realidade e eternizar a situação atual” (Idem, ibidem). Nesses termos, só se pode aspirar a transpassar a rigidez da coisificação cultural "em vestígios e escombros" onde "perdura a esperança de que alguma vez essa realidade chegue a ser uma realidade correta e justa" (Idem, ibidem).

Situada no contexto do mundo totalmente administrado, essa crítica das estratégias científicas e filosóficas totalizantes refere-se, particularmente, à rejeição da dialética praticada pela neo-ontologia de raiz fenomenológica, que pretende realizar uma exegese original (total) do ser. Assim, a pergunta "tal como a formulam expressamente os novos projetos ontológicos [...] e [...], em que pese toda classe de oposições, [...] também os sistemas idealistas que pretendem superar [...] já dá por assentado [...] que o simples Ser se adéqua ao pensamento e resulta acessível a ele" (Idem). Essa presunção de acessibilidade encarna "o paradoxo de toda ontologia na filosofia atual", dado "que o meio com o qual se trata de alcançar o Ser transubjetivo não é outro que a mesma ratio subjetiva do idealismo" (Idem, p. 106). Mais que isso, está em jogo a violência que a ratio identificadora exerce quando acolhe o conjunto da realidade numa única estrutura:

Sem dúvida, o sistema hegeliano deve pressupor a identidade de sujeito e objeto, e com isso a primazia do espírito que pretende demonstrar, mas em seu desdobramento concreto refuta a identidade, que adjudica à totalidade [...]. Seu círculo fechado origina a aparência sem fissuras do natural e, por fim, a metafísica do Ser. Mas a dialética continua e destrói essa aparência. Diante disso [...] Husserl quereria restabelecer a prima philosophia por meio da reflexão sobre o espírito purificado de todo traço do mero ente (Adorno, 1997e, pp.12-13).

O "primado do primeiro" - cuja forma mais acabada está representada no projeto da "ontologia fundamental" de Heidegger - orienta o método da redução fenomenológica, sendo, por isso mesmo, incompatível com o procedimento dialético, o qual procura incansavelmente a mediação em toda imediatez e realiza a crítica das filosofias do primeiro, mostrando que os conceitos supostamente "originários" se acham - todos eles, necessariamente e em si mesmos - mediados, obtendo sua originariedade da negação da mediação: 
[...] é tão impossível separar o espírito do dado, como o recíproco. Nenhum dos dois é um primeiro [...] mas, no entanto, se alguém pretendesse descobrir nesse mesmo estar mediado o princípio originário, estaria confundindo um conceito de relação com um conceito de substância, e reclamaria como origem o flatus vocis. A mediação não é uma asserção positiva a respeito do ser, mas sim uma instrução dada ao conhecimento no sentido de não deter-se diante de uma tal positividade. [...] Como princípio geral, a mesma desembocaria, uma e outra vez, como em Hegel, no espírito; com seu passe à positividade, torna-se não verdadeira (Idem, p. 32).

Desse modo, o primado do objeto que Adorno defende não atribui nenhuma prioridade ontológica, mas abre polemicamente a dialética (negativa) entre a subjetividade e o objeto de conhecimento como via para desarmar de dentro os efeitos da dominação no campo da cultura (científica). Ele representa "a intentio oblíqua da intentio oblíqua, não a intentio reta rediviva; é o corretivo da redução subjetiva, não a denegação da participação subjetiva" (Adorno, 1997b, p. 747). A primazia do objeto não implica, portanto, uma restauração da "servil confiança no ser-assim do mundo exterior", própria do pensamento pré-crítico. Longe de recair na crítica kantiana da mediação subjetiva presente na objetividade, ela exige uma segunda reflexão capaz de determinar a participação objetiva na mediação subjetiva. Tal reflexão mostra que a separação sujeito/objeto aconteceu historicamente e se deu sob o signo do domínio; mas mostra também que a postulação de uma indiferenciada unidade originária - "um estado de feliz identificação de sujeito e objeto" não é mais que uma ideologia histórica.

A unidade dessa dialética que retorna do objeto para negar a soberania do sujeito supõe uma modalidade da relação com a diferença - completamente anulada tanto na razão coisificada como na rebelião metafísica do romantismo. Por isso, numa passagem fundamental para essa discussão, Adorno afirma:

[...] se fosse possível especular sobre o estado de reconciliação, não caberia representar-se nele nem a indiferenciada unidade de sujeito e objeto, nem sua hostil antítese; antes bem, a comunicação do diferente [Kommunikation des Unterschiedenen]. Só então encontraria seu justo lugar, como algo objetivo, o conceito de comunicação. $\mathrm{O}$ atual é tão humilhante porque trai o melhor, o potencial de um acordo de homens e coisas, para entregá-lo ao intercâmbio entre sujeitos segundo os requerimentos da razão subjetiva. Em seu justo lugar estaria, também do ponto de vista da teoria do conhecimento, a relação de sujeito e objeto na paz realizada, 
tanto entre os homens como entre eles e seus outros [zwischen den Menschen wie zwischen ihnen und ihrem Anderen]. Paz é um estado de diferenciação sem subjugamento, no qual o diferente é compartilhado [das Unterschiedene teilhat aneinander] (Idem, p. 743).

Com o aparente anacronismo da dialética sujeito/objeto vemos que Adorno expõe um problema muito próximo daquele tratado por Habermas quando propôs a ação comunicativa como instância de crítica e superação da unilateralização do processo de racionalização social. No entanto, a diferença entre ambos os modelos de crítica das patologias sociais da razão surge em torno da estrutura e do diagnóstico da situação da comunicação no capitalismo tardio, e não a partir de uma suposta apelação romântica à reconciliação "do homem com a natureza: com os animais, as plantas e os minerais" (Habermas, 1987a, p. 485). A dialética negativa do objeto de conhecimento - a qual impede que o sujeito se feche sobre si mesmo como origem exclusiva de sentido - expõe efetivamente o horizonte crítico de uma "nova norma de verdade". Modalidade de relação não violenta com a alteridade, a comunicação é capaz de produzir a reforma da teoria do conhecimento.

A coincidência com Habermas não oculta, entretanto, a profunda diferença que existe entre ambos. $\mathrm{O}$ estímulo ao descentramento do sujeito - inerente ao conceito de comunicação - não vem agora da interpelação das pretensões de validade de outro sujeito que procura formalmente seu próprio reconhecimento - como no caso de Habermas -, mas é promovido, enigmaticamente, pelo objeto da controvérsia. Essa outra comunicação resiste ao "intercâmbio entre sujeitos segundo os requerimentos da razão subjetiva”, ao comércio das coisas através da linguagem diagnosticada por Adorno nas formas vigentes de comunicação. Se a comunicação possui algum efeito de conhecimento crítico, se promove um acordo entre os homens - diferente e contrário ao realizado pela razão identificadora - é porque conserva uma relação com a exterioridade, com os outros da relação de comunicação intersubjetiva, que são seus outros. A relação não violenta com essa instância opaca e excluída da alteridade - esta "diferença” com relação aos procedimentos racionalizados de reconhecimento intersubjetivo - aparece na tese de Adorno como o autêntico horizonte da racionalidade. "Compartilhar a diferença" é o que reclama uma prática do conhecimento que procura não esconder o procurado, pois o objeto achado sempre é capaz de afirmar novamente a diferença, o excesso do objeto em relação ao encontrado e, por conseguinte, também sua diferença em relação à procura em si mesma. 
Longe da interpretação irônica com a qual Habermas tentou descartar a radicalização da crítica praticada por Adorno, a autêntica controvérsia aparece quando, de um lado, se analisa em profundidade a relação entre linguagem e racionalidade que as teses sobre a "primazia do objeto" oferecem e, de outro, quando se reconstrói o conceito de interpretação sugerido nesse projeto. Intimamente relacionadas com aspectos substanciais e metodológicos das ciências sociais, ambas as questões requereriam em si mesmas um tratamento extenso que não podemos desenvolver aqui. No próximo item apresentaremos, em termos preliminares, um esboço geral de como abordá-las na obra de Adorno.

Linguagem, racionalidade, interpretação

Em vez de apresentar o conceito de comunicação como o outro absoluto da coisificação, o projeto de Adorno faz dele objeto de uma crítica que promove a sua reabertura dialética. Esta revela a comunicação internamente cindida, em relação dual com o fenômeno da coisificação. "Coisificante" já não é apenas a colonização da comunicação pela razão instrumental; é também o que se realiza em certo tipo de comunicação: a que exclui inclusive no sujeito aquilo que não se reduz a ele. "Coisificado" já não é só um mundo em que as relações inter-humanas e a subjetividade foram assimiladas ao mundo das coisas, no qual o entendimento linguístico não tem nenhuma validade; é também um mundo que se concebe a si mesmo como inteiramente intersubjetivo, no qual o entendimento linguístico vigente aparece como única e autossuficiente forma da verdade. Noutros termos, a crítica de Adorno à coisificação não funda um conceito transparente de comunicação, mas insiste em seus dilemas. E nessa insistência se reativa a dialética da comunicação, que oscila entre sua solidariedade à lógica do domínio subjetivo do mundo e seu potencial não violento, ou seja, capaz de fazer um esforço contra o esforço habitual de exclusão do qual emerge a cena dual da intersubjetividade.

A dialética da comunicação implica, por sua vez, a dialética da linguagem - já anunciada na Dialética do esclarecimento e para a qual Adorno retornou constantemente. Discutindo os limites da lógica discursiva, ele assinala, por exemplo, que "em virtude de seu caráter duplo" a linguagem é um constituinte da arte e seu inimigo mortal: "as ânforas etruscas de Villa Giulia falam muitíssimo e são incomensuráveis com toda a linguagem comunicativa. A verdadeira linguagem da arte é muda” (Adorno, 1997d, p. 171). Ao destacar a existência de uma "linguagem muda", Adorno não só 
sublinha a heterogeneidade fundamental entre as linguagens e a linguagem verbal como também desdobra e redescobre na própria linguagem sua dimensão "gestual". Se a obra expressa algo objetivo, o expressa também objetivamente: mostrando antes que explicando, "fazendo um gesto" pelo qual o objetivo se manifesta menos como sentido mais profundo e de difícil acesso que como marca, um rastro do heterogêneo em meio da comunicação discursiva e intersubjetiva, rastro do não subjetivo no sujeito: "a experiência da arte [...] é algo mais que uma vivência subjetiva: é a irrupção da objetividade na consciência subjetiva. [...] Sem necessidade de juízos, as obras de arte indicam como que com o dedo o seu conteúdo, mas sem convertê-lo em discursivo" (Idem, p. 363).

A "linguagem muda da arte" assinala (literalmente) isso que, na noção convencional da linguagem, aparece sempre reduzido ao que "é algo para outros": seu conteúdo espiritual. O gesto da arte revela a cena dual da intersubjetividade como cenário de uma hospitalidade devoradora. A noção convencional aparece aqui menos como destino de toda linguagem que como uma "maldição social" mostrada pela obra como tal: "o habitus linguístico do ser-assim-e-não-de-outro-modo é o médium em virtude do qual a maldição social se torna aparição. Mas Kafka, sabiamente, não a nomeia, por medo de que assim desapareça” (Idem, p. 342).

Não obstante o teor dessa argumentação, a dialética da linguagem e seu desdobramento não se restringem ao campo da arte. Assim como Benjamin (1999, p. 74) sustentou que "a linguagem não só significa comunicação do comunicável, mas também constitui de uma vez o símbolo do incomunicável”, Adorno também afirma o caráter paradoxal da linguagem em relação à comunicabilidade. A linguagem faz possível a comunicação e, nas condições atuais, transforma-a numa totalidade não verdadeira. Tal indicação é central para a posição dialética no campo das ciências sociais. Essa posição não se deixa levar "pelo geral entusiasmo comunicativo da sociologia subjetiva” (Adorno, 1972, p. 46). Ela afirma o caráter duplo da linguagem e rechaça tanto as exigências de depuração lógico-terminológica do conhecimento como de uma hermenêutica que interpreta subjetivamente o significado:

Interpretar é justamente o contrário de conferir um significado subjetivo da parte de quem conhece ou atua socialmente. A ideia desse modo de conferir significado induz erroneamente a afirmar que tanto o processo como a ordem social são algo inteligível para o próprio sujeito, intrínseco a ele, conciliado com ele e por ele jus- 
tificado. Um conceito dialético de significado não seria precisamente um correlato da compreensão significante weberiana; senão a essência social que cunha os fenômenos manifestando-se e ocultando-se ao mesmo tempo com eles. Uma essência que determina os fenômenos sem ser uma lei geral (Idem, p. 48).

$\mathrm{Na}$ Teoria estética, Adorno propõe deixar de compreender as obras de arte como objetos hermenêuticos, dado que "na situação atual o que deveríamos compreender é sua incompreensibilidade" (Adorno, 1997d, p. 179). Essa posição no debate sobre a relação entre linguagem e comunicação estabelece quais são, para ele, as possibilidades compartilhadas pela arte e pelo conhecimento social crítico. Não se trata de dissolver os elementos rigidificados da cultura contemporânea na cena dual intersubjetiva - movimento habitual nas ciências sociais, desde a fenomenologia e o existencialismo até a microssociologia e a teoria da ação comunicativa -, ou seja, de tentar explicá-los como um desvio das interações com sentido. $\mathrm{O}$ modelo crítico de Adorno tende a "exagerar" no lugar - isto é, sem reconduzi-los a outra cena da intersubjetividade ideal, do "contexto histórico" esclarecedor etc. - os efeitos da coisificação para que esta "se mostre" em traços os mais "afiados" e cortantes possíveis. $\mathrm{O}$ objetivo é fazer legível como tal o sem sentido desta essência social que cunha os fenômenos manifestando-se e ocultando-se ao mesmo tempo neles. Desse modo, na hora de citar formas de interpretação sociológica produtivas para a atualidade, Adorno se aproxima do modelo de crítica aos "horrores linguísticos" formulada por Karl Kraus, contrapondo-a produtivamente às diversas tendências vigentes na sociologia:

[...] os destroços cometidos no âmbito da linguagem eram para Kraus o sinal que anuncia a destruição real [...]. Os horrores linguísticos configurados por Kraus [...] são excreções dos processos sociais que começam por manifestar-se nas palavras, antes de destruir tenazmente a suposta vida normal da sociedade burguesa em que imperceptivelmente, e para além da usual observação científica, foram maturando. Daí que a fisionômica da linguagem desenvolvida por Kraus constitua uma chave para o conhecimento da sociedade muito superior à constituída pela maioria dos dados empírico-sociais, na medida em que dá conta sismograficamente dessa desnaturalização da qual a ciência, levada por um vaidoso apego à objetividade, nega-se obstinadamente a ocupar-se. [...] Pode ser que a sociologia contribua com mediações que Kraus desdenharia como mitigações de seus diagnósticos [mas] a fisionômica linguística de Kraus não teria exercido um influxo tão profundo na ciência e na filosofia da história se tivesse carecido do conteúdo de verdade dessas 
experiências básicas que o grupo em questão [o positivismo] desdenha como mera arte (Adorno et al., 1972, pp. 56-57).

O trecho evidencia um primeiro e claro requisito que Adorno propõe para toda interpretação em ciências sociais: a exigência de que o sujeito da interpretação seja capaz de assumir o caráter enigmático do existente. $\mathrm{O}$ enigmático não se revela como algo cheio de sentido, mas como algo insensato, ou seja, tanto opaco, resistente e frágil quanto urgente, provocador e perturbador. Sem dúvida, essa modalidade da experiência é o ponto de partida da ideia de interpretação de Adorno. Por isso, podemos afirmar que para ele a atividade interpretativa começa no encontro com "as figuras enigmáticas do existente e seus assombrosos entrelaçamentos" (Adorno, 1997f, p. 87). Isso talvez constitua uma das maiores constantes de sua prática reflexiva: se, na disputa com positivismo na sociologia alemã, alerta as ciências sociais dos anos de 1960 sobre a ilusão de inteligibilidade e racionalidade plenas da totalidade social contida nas noções centrais da hermenêutica, trinta anos antes, no contexto de outro debate, havia sustentado que "não é tarefa da filosofia expor nem justificar o sentido como algo positivamente dado, nem a realidade como 'cheia de sentido"' (Idem, ibidem).

O movimento da interpretação materialista que Adorno propôs não consiste, portanto, em investigar intenções ocultas e preexistentes da realidade senão, pelo contrário, em interpretar, inclusive objetos carentes de intenções, através da construção de figuras compostas com elementos isolados da realidade (Idem, p. 335). Essa construção de modelos interpretativos ilumina a realidade de tal modo que alguns de seus perfis enigmáticos se revelam e ficam em movimento graças ao trabalho do intérprete. Como ele afirma em 1930, essa ideia deixa vislumbrar a possível afinidade entre interpretação e materialismo, entendendo por "materialismo" um tipo de pensamento que desloca com o máximo rigor a primazia do intencional, da significação já dada na realidade, e só concebe como autênticas aquelas interpretações que mostram potência suficiente para transformar as perguntas.

Podemos conjeturar que o essencial dessa ideia de interpretação consiste em abranger dentro do esforço hermenêutico das ciências sociais aqueles objetos que não se apresentam como objetos hermenêuticos. Esta é a principal diferença entre Adorno e Habermas, especialmente se pensarmos na análise da modernidade tardia. Se para este último - seguindo uma larga tradição no interior da filosofia analítica da linguagem - só são suscetíveis de interpretação aqueles fenômenos sociais surgidos no mundo da vida a partir do uso de 
meios linguísticos, a tese adorniana sobre a primazia do objeto propõe uma ampliação do universo do que deve ser suscetível de interpretação no mundo coisificado do capitalismo tardio. Procurando ler nas ruínas rigidificadas dos objetos ambíguos da modernidade - que não são estritamente nem objetos com sentido nem sem -, Adorno propõe um conceito de interpretação que transcende as fronteiras da racionalidade intersubjetiva e os limites infranqueáveis consagrados pelas ciências sociais tradicionais.

\section{Referências Bibliográficas}

Adorno, Theodor. (1964), Minima Moralia. Frankfurt, Suhrkamp. . (1997a), Negative Dialektik. Frankfurt, Suhrkamp. (1997b), "Kulturkritik und Gesellschaft". In: Gesammelte Schriften. Frankfurt, Suhrkamp, vol. 10.2, pp. 455-844. (1997c), "Soziologische Schriften”. In: Gesammelte Schriften. Frankfurt,

Suhrkamp, vol. viII, pp. 4-408. . (1997d), "Ästhetische Theorie". In: Gesammelte Schriften. Frankfurt,

Suhrkamp, vol. vII, pp. 7-545. (1997e), "Zur Metakritik der Erkenntnistheorie". In: Gesammelte Schriften. Frankfurt, Suhrkamp, vol. v, pp. 9-247. . (1997f), "La actualidad de la Filosofía". In: Actualidad de la filosofía.

Barcelona, Altaya, pp. 73-102.

Adorno, Theodor \& Horkheimer, Max. (1997), “Dialektik der Aufklärung” In: Adorno, Theodor. Gesammelte Schriften. Frankfurt, Suhrkamp, vol. III, pp. 9-336. Adorno, Theodor et al. (1972), La disputa del positivismo en la sociología alemana. Barcelona/México, Grijalbo.

Aguilera, Antonio. (1997), "Introducción: Lógica de la descomposición”. In: Adorno,

Theodor. Actualidad de la filosofía. Barcelona, Altaya, pp. 9-70.

Benjamin, Walter. (1999), "Sobre el lenguaje en general y sobre el lenguaje de los humanos". In : Iluminaciones. Madrid, Taurus, vol IV, pp. 59-74

Habermas, Jürgen. (1987a), Teoría de la acción comunicativa. Madrid, Taurus, vol. 1. (1987b), Teoría de la acción comunicativa. Madrid, Taurus, vol. 2.

Herder, Johann Gottfried. (1959), Ideas para una filosofia de la historia de la humanidad. Buenos Aires, Losada.

(1986), "Entendimento e experiência: uma metacrítica à Crítica da razão pura", In: Justo, José M. (org.) Ergon ou energeia: filosofia da linguagem na AlemanhaSéculos XVIII e XIX. Lisboa, Apaginastas, pp. 59-100. 
Honneth, Axel. (1991), The critic of power: reflective stages in a critical social theory. Massachusetts, MIT Press. (1995), The fragmented world of the social. New York, State University of New York.

Horkheimer, Max. (1967), Zur Kritik der instrumentellen Vernunft. Frankfurt, Suhrkamp.

Morris, Martin. (2001), Rethinking the communicative turn: Adorno, Habermas and the problem of communicative freedom. New York, State University of New York. Pollock, Friedrich. (1989), "State capitalism: its possibilities and limitations". In: Bronner, Stephen e Kellner, Douglas (orgs.) Critical theory and society. New York, Routledge, pp. 95-118.

\section{Resumo}

O objeto das ciências sociais e a virada comunicativa: Adorno após Habermas

$\mathrm{O}$ artigo procura reconsiderar as críticas de Jürgen Habermas à teoria social de Theodor Adorno. Inicialmente, analisamos as razões apresentadas por Habermas para abandonar a crítica dialética do processo de racionalização social. Em seguida, para expor nossas objeçōes a essa interpretação, reconstruímos duas teses que, embora essenciais à crítica de Adorno ao processo de modernização vigente, foram deslocadas pelo paradigma da ação comunicativa. Por fim, através da relação entre linguagem e racionalidade que Adorno estabelece, sugerimos um tratamento diferente ao lugar da comunicação na constituição das sociedades contemporâneas.

Palavras-chave: Habermas; Adorno; Teoria crítica; Racionalidade; Linguagem.

\section{Abstract}

The object of social sciences and the communicative turn: Adorno after Habermas

The article intends to reconsider the critique of Theodor Adorno's Social Theory formulated by Jürgen Habermas. In the first part of the text we analyze in detail the reasons Habermas enounces to leave behind the dialectical criticism of the process of social rationalization. In order to put forward our objections to Habermas' interpretation we reconstruct, in the second part, two essential thesis, which became displaced by the paradigm of communicative action, and which had served Adorno to elaborate his criticism of the prevailing modernization process. As a conclusion, we propose a different understanding of the roll played by communication in the constitution of contemporary societies, through an analysis - based upon Adorno - of the relationship between language and rationality.

Keywords: Habermas; Adorno; Critical Theory; Rationality; Language.

Texto recebido em 14/2/2010 e aprovado em 15/8/2011.

Gisela Catanzaro é doutora em Ciências Sociais pela Universidade de Buenos Aires e pesquisadora do Conselho Nacional de Investigaçōes Científicas e Técnicas (Conicet). E-mail: <giselacatanzaro@yahoo.com>.

Ezequiel Ipar é doutor em Filosofia pela USP e pesquisador do Conicet. E-mail: <ezequielipar@ yahoo.com>. 
